\title{
Aprendizagem Baseada em Projetos e Gestão da Saúde: aproximando teoria e realidade no Sistema Único de Saúde
}

\author{
Maria Eduarda de Andrade*; Eduarda Renata Ariotti*; Carla Moretto*; Aline Macarevich \\ Condessa** \\ * Graduanda do Curso de Odontologia, Universidade do Vale \\ do Taquari \\ ** Doutora em Odontologia - Saúde Bucal Coletiva pela \\ Universidade Federal do Rio Grande do Sul
}

Recebido: 29/03/2019. Aprovado: 18/11/2020.

\begin{abstract}
RESUMO
O Curso de Odontologia da Universidade do Vale do Taquari (UNIVATES) é organizado em um currículo modular integrado, baseado nas metodologias ativas de ensino aprendizagem. O objetivo deste estudo é relatar a experiência de discentes e docente sobre a metodologia 'aprendizagem baseada em projetos' adotada no eixo de Saúde, Sociedade, Cidadania e Direitos Humanos VI do Curso de Odontologia em 2018. Os estudantes foram divididos em pequenos grupos para realizarem 3 atividades principais: caso problema inicial sobre gestão em saúde; oficina de sistemas de informação em saúde; e projeto de implementação de serviço de saúde bucal. Após a realização de cada atividade, os estudantes apresentavam ao grande grupo, para uma análise dialogada. Buscou-se entender o contexto existente nos espaços de saúde, desde a gestão até o cuidado direto ao usuário. Realizou-se visita nas Unidades de Saúde, análise dos planos municipais, acompanhamento das atividades e dos profissionais, conversa com os usuários, buscas de dados nos sistemas de informação em saúde, além de análise na forma de contratação dos profissionais. Conclui-se que os discentes refletiram sobre o desafio da gestão ao lidar com as demandas dos usuários e profissionais do Sistema Único de Saúde (SUS). O ensino foi aprimorado e qualificado, permitindo que os discentes e futuros profissionais construíssem uma percepção mais crítica e ampliada da rede de atenção em saúde bucal. Essas reflexões, baseadas em situações da prática da equipe de saúde bucal, buscam qualificar os processos de trabalho na medida em que forma estudantes voltados para o SUS.
\end{abstract}

Descritores: Aprendizagem. Educação em Odontologia. Saúde Coletiva. Relatos de Caso. Gestão em Saúde.

\section{INTRODUÇÃO}

Tradicionalmente, a metodologia utilizada na educação das profissões na área da saúde é constituída com o professor como o centro do conhecimento e dos conteúdos apresentados nos cursos, e o aluno como mero ouvinte ${ }^{1}$. Por muitos anos, os cursos de Odontologia apoiavam a formação em sua prática individual, voltada ao 
mercado privado da profissão, tendo a fragmentação de conteúdo do ensino e da prática, com professores orientadores especialistas ${ }^{2}$. No entanto, as exigências atuais para os profissionais da saúde pressupõem um modelo de pensar inovador com um olhar crítico sobre as ações desenvolvidas, com profissionais capazes de atuar tanto no setor público quanto no privado ${ }^{1}$.

A Odontologia também precisa atualizar suas metodologias de ensino para acompanhar as necessidades da população e dos profissionais de saúde que atuam cada vez mais de forma interdisciplinar ${ }^{3}$. Desde a publicação das Diretrizes Curriculares Nacionais (DCN) ${ }^{4}$ em 2002, o ensino odontológico modifica-se lentamente, corroborando para a formação de profissionais mais preparados e capacitados para atuarem no Sistema Único de Saúde (SUS), bem como nas ciências humanas e sociais. Muitos cursos de Odontologia já lançam mão de diversas metodologias ativas de aprendizagem como estratégias e ferramentas pedagógicas para qualificar o ensino ${ }^{5,6}$.

As metodologias ativas de aprendizagem podem contribuir para o desenvolvimento das habilidades desejadas no perfil do formando egresso em Odontologia. De acordo com as DCN, espera-se que os graduados em Odontologia tenham uma formação generalista, humanista, crítica e reflexiva, para atuar em todos os níveis de atenção à saúde, com base no rigor técnico e científico ${ }^{4}$. As metodologias ativas são estratégias, técnicas, abordagens e perspectivas de aprendizagem individual e colaborativa que envolvem e engajam os acadêmicos no desenvolvimento de projetos e atividades práticas. São formas de desenvolver o processo do aprender que os professores utilizam para uma formação crítica de futuros profissionais. Isso favorece a autonomia do acadêmico, despertando a curiosidade, estimulando tomadas de decisões individuais e coletivas, pela prática social ${ }^{7}$. A potencialidade formadora da metodologia ativa configura uma importante estratégia de ensino do profissional da saúde, com base na expectativa de acentuada autonomia. Espera-se que esses profissionais sejam capazes de resolver problemas por meio de uma análise global do contexto de cada caso $^{8}$.

A Aprendizagem Baseada em Projetos (ABP) caracteriza-se por ser uma modalidade de aprendizagem ativa e colaborativa na qual os alunos formam grupos com tarefas de pesquisa e/ou investigação 9 . Ao estimular o pensamento crítico dos estudantes, por meio da coleta de informações, formulação e refinamento de perguntas, predições e compartilhamento de ideias e conclusões, há um maior envolvimento dos alunos com o conteúdo de aprendizagem ${ }^{10}$.

$\mathrm{Na}$ Odontologia, a ABP também está conquistando espaço, oportunizando o desenvolvimento de projetos de desenvolvimento de tecnologias ${ }^{11}$ quanto para o ensino de disciplinas básicas $^{12}$. No entanto, não foram encontrados estudos sobre a utilização da ABP no processo de trabalho em Odontologia, em especial nas questões relacionadas à gestão. Independente da estratégia de ensino, o tema da gestão em saúde é, em geral, pouco trabalhado na graduação em Odontologia, com pouca carga horária e mais para o final do curso $^{13}$. Por ser um tema desconhecido para a maioria dos estudantes, o desafio ao educador é ainda maior.

Diante do exposto, o objetivo deste artigo é relatar a experiência de discentes e docente sobre a metodologia de aprendizagem baseada em projetos (ABP) adotada para a condução do tema Gestão em Saúde no eixo de Saúde, Sociedade, Cidadania e Direitos Humanos VI do Curso de Odontologia da Universidade do Vale do Taquari (UNIVATES).

\section{RELATO DA EXPERIÊNCIA}

O relato de experiência de caráter descritivo e exploratório teve como cenário de pesquisa as 
aulas de graduação em Odontologia do eixo de Saúde, Sociedade, Cidadania e Direitos Humanos (SSCDH) VI.

O curso de Odontologia da UNIVATES, instituição privada sem fins lucrativos, situa-se no município de Lajeado, Rio Grande do Sul, e adotou como modelo a metodologia ativa de ensino e aprendizagem. A Instituição de Ensino Superior (IES) oferta aos professores capacitações e programas de educação permanente, para que possam lançar mão de diferentes metodologias em suas aulas.

O curso de Odontologia possui carga horária total de 4.200 horas divididas em dez módulos (semestres), totalizando cinco anos. O modelo modular foi escolhido buscando trabalhar os conteúdos de forma integrada, sem a divisão em disciplinas. Dentro de cada módulo, os conteúdos são divididos em 4 eixos diferentes: Saúde, Sociedade, Cidadania e Direitos Humanos (SSCDH); Educação Permanente (EP); Organização dos Processos de Trabalho em Saúde (OPTS) e Integralidade da Atenção à Saúde (IAS). O curso foi estruturado a partir das competências almejadas nas DCN para mudar o quadro de saúde geral da população, por meio do exercício pleno da atenção à saúde, da liderança frente às necessidades da população e da comunicação necessária para o trabalho interprofissional.

No sexto semestre da graduação (módulo 6), o eixo de SSCDH VI tem como objetivo a análise dos sistemas de saúde pública e privada na perspectiva do modo de produção de cuidado e a gestão de sistemas e serviços de saúde com ênfase na rede de serviços. Para tanto, buscou-se a compreensão do conceito de gestão em saúde, identificação e planejamento de ações considerando a pluralidade regional e nacional; a identificação e utilização de ferramentas de gestão em saúde; e a compreensão da gestão do processo de trabalho das equipes de saúde, aliado à avaliação em saúde.
O eixo foi dividido em 18 encontros semanais, totalizando a carga-horária de 60 horas semestrais, 3,30 horas por encontro. Os 15 estudantes que compuseram a turma foram divididos em grupos para todas as atividades principais, compondo grupos mistos, com estudantes de características e perfis distintos. Utilizou-se o município fictício de Três Coquinhos para condução da tarefa inicial e os municípios nos quais os alunos realizavam estágios para as demais atividades. Todas as atividades do eixo SSCDH VI foram realizadas no laboratório de informática da IES.

\section{Caso problema inicial}

Como disparador dos assuntos a serem trabalhados no semestre, foi apresentado um caso problema sobre a gestão da saúde pública e as principais dificuldades enfrentadas para atender de forma equânime as demandas de saúde da população, bem como a reflexão sobre a melhor forma de organizar a gestão.

Três Coquinhos é um município do norte do estado do Rio Grande do Sul, com cerca de 30 mil habitantes. O Secretário de Saúde, sr. Paulo, foi empossado no início de 2018, quando o Secretário de Saúde anterior foi destituído do cargo, pois a população estava muito descontente com os serviços de saúde e as reclamações na rádio local eram constantes. Paulo não tem formação técnica na área da saúde, mas quer agradar a população para não ter o mesmo destino do gestor anterior. $O$ problema é que ele não tem ideia de como melhorar os serviços de saúde, visto que a verba pública é escassa e as demandas vêm de todos os lados: unidades básicas de saúde, consultas especializadas, hospital, medicações, processos judiciais, etc. $O$ prefeito, que é cunhado de Paulo, disse que 
o apoiaria, contanto que a população parasse de reclamar dos serviços.

Frente à situação apresentada, em sala de aula, foi proposta a problematização dos seguintes pontos norteadores:

1) Por onde o Secretário de Saúde deve começar?

2) O que ele precisa saber para fazer a gestão da saúde em Três Coquinhos?

3) Com quem ele deve conversar?

4) Quais são as informações necessárias para uma boa gestão?

5) Onde ele conseguirá as informações necessárias?

6) O que é gestão?

7) Quem participa da gestão no SUS?

8) Que ferramentas de gestão o Secretário pode lançar mão?

As atividades foram realizadas em um espaço da universidade que dispunha de computadores e rede de internet para busca de informações. Os estudantes tiveram uma semana para finalizar a atividade (extraclasse) e na aula seguinte as respostas foram apresentadas e discutidas no grande grupo. As dúvidas foram levantadas e sanadas neste momento. Foram utilizados 2 encontros para o Caso Problema Inicial.

Esta atividade induziu os estudantes a pensar e refletir sobre problemas reais do cotidiano das gestões municipais de saúde, visualizando a perspectiva dos três atores envolvidos: gestor, profissional e usuário. Dessa forma, o estudante pode criar situações favoráveis para a resolução do problema, pesquisando e estudando os assuntos abordados de forma crítica.

Pelo fato da dinâmica ser feita em trio, os estudantes compartilharam ideias e pensamentos fazendo com que a construção do trabalho fosse ainda mais enriquecedora e dinâmica, induzindo o diálogo que é de suma importância na construção do conhecimento. Após esse período de construção, reflexão e discussão no trio, o produto foi levado ao grande grupo, montando um trabalho de quebra-cabeça com reflexões muito mais profundas e abrangentes.

À professora coube a tarefa de definir o rumo geral da aula no primeiro momento, disponibilizando conteúdo para que embasasse a continuação do estudo/pesquisa do estudante no segundo momento de aula. Os discentes opinaram e auxiliaram a professora no desenvolvimento da tarefa, mas a orientação final era responsabilidade da docente. Para a professora, que não havia acompanhado a turma no semestre anterior, a realização de um caso inicial foi uma boa ferramenta para averiguação do nível de conhecimento teórico dos estudantes, além da avaliação do posicionamento crítico e da dinâmica em grupo.

Nesse sentido, o docente recapitula o conteúdo abordado em semestres e eixos anteriores e aborda de forma diversa os conteúdos necessários para a construção do conhecimento. Colocando-se à disposição da turma, demonstra interesse nas diversas necessidades de aprendizado. Além disso, essa imposição de poder pelo professor não ocorre, adotando a postura mediadora entre o conhecimento teórico a que se propõe trabalhar e o conhecimento prévio dos discentes. Mesmo que o estudante não demonstre interesse no assunto, ou que ele não se envolva de forma profunda com o conteúdo e o trabalho, ele é responsável por tarefas específicas dentro do pequeno grupo e é estimulado a participar do diálogo da turma.

\section{Oficina de sistemas de informação em saúde}

Frente à necessidade de informações, dados e indicadores levantada no caso problema inicial, foi proposta uma Oficina sobre Sistemas de Informação em Saúde (SIS). No primeiro momento da aula, os estudantes foram apresentados aos principais SIS. Então foram divididos em grupos e conduzidos à coleta de dados dos municípios onde 
os estudantes realizavam seus estágios curriculares.

No segundo momento, foi disponibilizado um Caso Problema para nortear a utilização e interpretação dos dados a serem obtidos nos sistemas de informação em saúde.

Você passou no concurso para a prefeitura de Três Coquinhos e foi convidado a assumir o cargo de Gestor de Saúde Bucal do município. O prefeito acha que a equipe de Saúde Bucal não está trabalhando bem e pediu que você verificasse a produção mensal. Além disso, ele sabe que existem verbas que o município pode receber e ele quer mais dinheiro, mas atualmente não tem ninguém controlando isso.

Para responder ao prefeito, realize a análise situacional do município onde você está fazendo o estágio, contendo:

-Informações do Cadastro Nacional de Estabelecimentos de Saúde (CNES) da UBS/CEO.

-Informações da SAGE quanto a Redes $e$ Programas; Gestão e Financiamento;

-Análise dos 3 indicadores de saúde bucal do IDSUS (calcular, no mínimo, o indicador $\left.n^{\circ} 21\right)$;

-Produção ambulatorial dos

procedimentos odontológicos do

município nos meses de julho a dezembro de 2017.

Neste projeto, também foi solicitado que os estudantes discutissem as Portarias Ministeriais que regulamentam o incentivo financeiro para a Saúde Bucal na Atenção Básica e na Atenção Secundária; o controle da produção ambulatorial realizada pelos dentistas do SUS; a forma de pagamento na atenção básica e na atenção secundária e a existência de meta de saúde bucal. Por fim, os grupos redigiram um documento oficial para entregar ao prefeito.

Em função da complexidade da tarefa, foi disponibilizado tempo em aula para a coleta e interpretação dos dados. Durante o desenvolvimento da atividade, os estudantes sentiram necessidade de um arcabouço teórico sobre Financiamento em Saúde e a professora elaborou uma aula expositiva dialogada, compilando os conceitos básicos e as principais portarias do Ministério da Saúde. Foram utilizados 8 encontros presenciais para a condução das atividades que compuseram a Oficina de Sistemas de Informação em Saúde.

Após o estudo, o trabalho foi apresentado para o grande grupo. A professora não definiu a forma de apresentação, e os estudantes optaram pela maneira que julgaram mais pertinente e didática, por meio de slides, texto e cartazes. Abrir mão de decisões tradicionalmente realizadas pelos professores não ocorre de forma natural, e é um exercício para os docentes que desejam trabalhar de forma sistêmica e horizontal com os estudantes.

Do ponto de vista discente, sem dúvidas a atividade foi mais complexa, que necessitava de atenção e dedicação extrema dos estudantes para sua concretização. Essa tarefa foi um separador de águas, pois os estudantes entenderam o quão desafiador é trabalhar na atenção primária à saúde, vendo seus supervisores locais de estágio com outros olhos. Os discentes perceberam o quanto o cirurgião-dentista, mesmo sem estar na coordenação da UBS, tem papel fundamental na procura por incentivos que melhorem a atenção à saúde bucal dos usuários do SUS juntamente com a gestão. Além disso, a busca nas bases de dados foi feita de forma autônoma, e os estudantes vivenciaram a complexidade desses sistemas, coletando informações que devem ser utilizadas para o planejamento em saúde. É importante salientar que, mesmo utilizando um município fictício no enunciado da tarefa, os estudantes trabalharam na coleta de informações dos municípios onde realizavam seus estágios, trabalhando com os problemas reais percebidos no dia a dia da equipe de saúde. Cabe informar que os 
estágios curriculares fazem parte do eixo de Educação Permanente (EP), no qual os estudantes vivenciam o processo de trabalho na Atenção Primária e na Atenção Secundária em Saúde, ao longo dos semestres. O eixo de SSCDH é exclusivamente teórico.

\section{Projeto de implementação de serviço de saúde bucal}

Após a entrega, discussão e avaliação da Oficina sobre SIS, os estudantes receberam um ofício com a resposta do prefeito da cidade fictícia, solicitando a elaboração de um Projeto de Implementação de Serviço de Saúde Bucal.

Prezado cirurgião-dentista,

Coordenador de Saúde bucal

A análise situacional realizada por sua equipe foi profunda e abrangente. As propostas foram embasadas nas necessidades de saúde da população e na possibilidade de maiores repasses financeiros por meio de incentivos federais. Considerando os dados apresentados e as alternativas sugeridas para a melhoria $d a$ rede de atenção à saúde bucal do município, solicito um projeto de implantação de um serviço odontológico que contribuirá para a melhora dos índices de saúde da nossa população.

Agradeço seu empenho na busca pela ampliação do acesso e qualificação do atendimento prestado aos nossos munícipes.

Aguardo o projeto em até 90 dias, a contar da data deste ofício.

Os estudantes foram divididos em grupos de quatro integrantes e as tarefas foram apresentadas em aula expositiva. Os grupos escolheram um tipo de serviço odontológico a ser instalado no município (ESB vinculada à ESF, ESB vinculada à UBS tradicional ou à Unidade Odontológica Móvel); identificaram os trâmites necessários para a instalação de novos serviços (guiados pela conversa com a representante da Secretaria Estadual de Saúde); leram as portarias e políticas nacionais que regulamentam os serviços odontológicos, as atribuições da equipe de saúde bucal na Política Nacional de Atenção Básica de 2017, materiais disponibilizados pelo Ministério da Saúde, protocolos de saúde bucal, livros e artigos sobre a temática (quadro 1); elaboraram um levantamento das necessidades em saúde da população a ser atendida pelo novo serviço; organizaram uma agenda levando em conta a demanda espontânea, urgência e consultas programadas, além das atividades multidisciplinares/intersetoriais. Os estudantes também trabalharam na construção da rede de cuidados em saúde bucal (fluxos) no município, pensando nas equipes de referência e contrarreferência, definiram a forma de contratação de RH (nova equipe) e o modelo de gestão da equipe.

As leituras recomendadas foram disponibilizadas previamente de forma online pela biblioteca virtual da UNIVATES ou em forma física, também na biblioteca. Os artigos também eram enviados por e-mail pela professora (quadro 1). Em cada aula havia o primeiro momento para discussão teórica e aproximação com a realidade do estágio/vivência dos estudantes baseados na leitura prévia; e o segundo momento, no qual os grupos elaboraram seus projetos.

Todas as atividades foram realizadas no laboratório de informática da IES, visando à produção diária das atividades, aliando a teoria à prática. $\mathrm{O}$ projeto foi entregue à educadora e apresentado aos demais colegas. Por fim, discutiram-se as particularidades, vantagens $\mathrm{e}$ desvantagens das principais escolhas. Foi pactuado no início do semestre qual seria o andamento previsto para o eixo SSCDH. A cada atividade, a professora explicava quais eram os objetivos, as formas de trabalho aceitas e o tipo de avaliação. 
Devido à necessidade de explanação teórica sobre Financiamento em Saúde levantada pelos discentes, houve repactuação de prazos, com aumento do tempo em aula para a realização das atividades e aula expositiva dialogada conduzida pela professora.

Quadro 1. Leituras recomendadas por aula, de acordo com o assunto a ser abordado

\begin{tabular}{|c|c|}
\hline ASSUNTO & LEITURA RECOMENDADA/ATIVIDADE \\
\hline $\begin{array}{l}\text { Gestão Saúde Bucal no SUS } \\
\text { Convidada Cirurgiã-dentista da Secretaria Estadual } \\
\text { de Saúde (SES-RS) }\end{array}$ & $\begin{array}{l}\text { Portarias Ministeriais e Estaduais sobre implementação de serviços de } \\
\text { saúde bucal }\end{array}$ \\
\hline $\begin{array}{l}\text { Avaliação da organização da agenda/demanda dos } \\
\text { locais de estágio }\end{array}$ & Busca e análise de um artigo sobre organização de demanda em Saúde Bucal \\
\hline $\begin{array}{l}\text { Experiências e práticas de Saúde Bucal na } \\
\text { Estratégia de Saúde da Família }\end{array}$ & $\begin{array}{l}\text { Moysés ST, Kriger L, Moysés SJ. Saúde bucal das famílias: trabalhando com } \\
\text { evidências. São Paulo: Artes Médicas, } 2008 .\end{array}$ \\
\hline Formas de contratação no SUS & $\begin{array}{l}\text { Lara SM, Bordin R, Costa Filho LC. Remuneração dos serviços de saúde } \\
\text { bucal: formas e impactos na assistência. Cad Saúde Pública. 2002; 18(6): } \\
\text { 1551-59. } \\
\text { Morais HM, Oliveira RS. O trabalho em saúde e os desafios para o SUS. } \\
\text { In: Moysés SJ, Goes PSA. Planejamento, gestão e avaliação em saúde } \\
\text { bucal. São Paulo: Artes Médicas, 2012. p. 93-100. }\end{array}$ \\
\hline $\begin{array}{l}\text { Administração pública e modelos de gestão em } \\
\text { saúde }\end{array}$ & $\begin{array}{l}\text { Alcântara CM. Fundamentos da administração pública e novos modelos de } \\
\text { gestão em saúde. In: Moysés SJ, Goes PSA. Planejamento, gestão e } \\
\text { avaliação em saúde bucal. São Paulo: Artes Médicas, 2012. p. 83-89. }\end{array}$ \\
\hline Gestão por resultados & $\begin{array}{l}\text { Ditterich R, Moysés SJ. Gestão baseada em resultados e processos de } \\
\text { contratualização. In: Moysés SJ, Goes PSA. Planejamento, gestão e } \\
\text { avaliação em saúde bucal. São Paulo: Artes Médicas, 2012. p.113-122. }\end{array}$ \\
\hline Apoio Institucional & $\begin{array}{l}\text { Barros RS, Sousa LMO, Dias PB, Díaz PHP, Soster JC, Heinzelmann RS, et } \\
\text { al. Gestão participativa e controle social. In: In: Moysés SJ, Goes PSA. } \\
\text { Planejamento, gestão e avaliação em saúde bucal. São Paulo: Artes Médicas, } \\
\text { 2012. p.135- } 142 \text {. } \\
\text { Utilização de caso problema para discutir o papel do apoiador institucional } \\
\text { na atenção básica }\end{array}$ \\
\hline $\begin{array}{l}\text { Apoio matricial }- \text { equipe de referência e } \\
\text { contrarreferência }\end{array}$ & $\begin{array}{l}\text { Campos D. Apoio matricial e equipe de referência: uma metodologia para } \\
\text { gestão do trabalho interdisciplinar em saúde. Cad Saúde Pública. 2007; } \\
\text { 23(2):399-407. }\end{array}$ \\
\hline
\end{tabular}

Além dos temas propostos inicialmente pela docente, os estudantes levantaram questões reais vividas no eixo de Educação Permanente (EP), onde realizam estágio em Unidades Básicas de Saúde (UBS) e Centro de Especialidades Odontológicas (CEO). Essa aproximação da teoria e da prática trouxe ainda mais sentido para o estudante, tornando a aprendizagem significativa. Oito encontros presenciais foram disponibilizados para a realização Projeto de Implementação de Serviço de Saúde Bucal.

Os estudantes avaliaram a atividade como extremamente trabalhosa, mas que deveria ser realizada por todos os cursos da área da saúde. É nesse momento que o estudante se coloca integralmente como responsável pelo acontecimento de algo importante e fundamental, palpável e difícil de ser realizado. Entende-se a complexidade e o quão trabalhoso é estar inserido num serviço público e como os futuros profissionais devem ter um papel ativo e colaborar para a construção uma sociedade com mais acesso à saúde bucal.

\section{DISCUSSÃO}

Vários são os desafios que motivam um olhar singular às novas perspectivas com relação à formação discente. Os desafios somam-se no pensar, elaborar, questionar, intervir e planejar as mais novas práticas e técnicas que permeiam o 
processo de trabalho do cirurgião-dentista no SUS. A liberdade para construir o trabalho pode gerar insegurança nos discentes sobre qual caminho deve tomar primeiro na sua construção. Da mesma forma, a docente trabalhou sua vulnerabilidade, na medida em que a aula não estava completamente sob seu controle. Os assuntos levantados pelos estudantes quando relacionavam as leituras aos ambientes de estágio ao mesmo tempo em que enriqueceram as trocas, fizeram com que a professora desenvolvesse suas habilidades didáticas e de pensamento crítico.

A organização da gestão e o debate crítico sobre os sistemas de cuidado em saúde normalmente não são trabalhadas na formação dos profissionais, dificultando a estruturação do cuidado e o controle social sobre o setor da saúde $^{13,14}$. No entanto, novas abordagens para aproximar os estudantes da gestão do SUS podem propiciar uma contínua problematização e uma visão ampliada e transformadora da gestão, aliando estratégias para simultaneamente aprender, ensinar e prover informações para gestão e tomada de decisão no SUS ${ }^{15}$. Esse tempo dedicado em sala de aula é de fundamental importância para o futuro da saúde pública do país, pois os acadêmicos têm a oportunidade de entender melhor sobre gestão, ainda que não intervindo diretamente. Conhecer a realidade complexa e discutir com os colegas e professores enriquece a construção do conhecimento. No âmbito pedagógico, isso favorece o olhar crítico do estudante, sua maneira de pensar e agir sobre os problemas, dificuldades, enfrentamentos e divergências encontradas, além de motivar a busca da resolutividade dos problemas encontrados.

A educação deve ser vista como um processo que envolve ação-reflexão-ação, seguindo um modelo dialógico e pautado nas realidades locais e conhecimentos prévios dos estudantes ${ }^{16}$. Utilizando os ambientes e dificuldades percebidas pelos discentes em seus locais de estágio no SUS, foi possível realizar uma reflexão crítica sobre gestão em saúde. A educadora buscou desenvolver um diálogo horizontalizado com a turma, em um espaço dinâmico de aprendizagem e troca de conhecimentos. Esse modelo também contribuiu para a formação de vínculo da professora com os estudantes. Com uma postura aberta e rompendo com o autoritarismo e a tentativa do convencimento pelo medo (em relação ao professor, ao conteúdo, à avaliação), as relações em sala de aula foram mais saudáveis e propositivas. A busca pela construção do conhecimento é de todos, não apenas dos estudantes, pois há o reconhecimento de que todos sabem algo e que podem agregar conhecimento e sabedoria aos demais.

As DCN reforçam nitidamente a importância do trabalho em equipe interdisciplinar com extrema produtividade na promoção de saúde ${ }^{4}$. $\mathrm{O}$ trabalho em equipe, por meio de um projeto a ser elaborado, contribui para o desenvolvimento das habilidades e competências necessárias ao cirurgião-dentista, como a comunicação, a tomada de decisão e a gestão em saúde. Em estudo realizado em uma universidade brasileira, os estudantes de graduação em Odontologia relataram preferência e satisfação quanto ao trabalho em equipe desenvolvido por meio da abordagem baseada em equipes, propiciando maior sentimento de responsabilidade ${ }^{17}$.

Da mesma forma, a liderança e autonomia foram trabalhadas neste plano de atividades. Não basta esperar que o profissional de Odontologia seja capaz de assumir a liderança em equipe. Ele precisa ter tido, durante sua formação, oportunidades concretas de desenvolver esse papel, para ter condições de planejar estratégias contínuas, administrar e gerenciar serviços e aprender permanentemente ${ }^{18}$. 
O papel do educador em metodologias ativas de aprendizagem também é crucial. Ele deve ser ativo, envolvido com os estudantes e consciente de que também precisa se atualizar permanentemente. Ele sai do centro e domínio total do conhecimento, e torna-se um facilitador/orientador do processo de construção, estimulando o aluno como o sujeito da sua aprendizagem $^{14}$. Isto não desobriga o professor a ter autoridade e a dar limites, mas combate o autoritarismo desenfreado, que cria uma barreira entre professor e a turma ${ }^{19}$. O conhecimento teórico do docente também é fundamental para que o mesmo tenha credibilidade com a turma. $\mathrm{O}$ fato de realizarem juntos a construção do conhecimento não exime o professor de estudar e saber como conduzir as discussões em aula. É necessário que o docente construa um vínculo com a turma, demonstrando conhecimento teórico e manejo didático para incluir os estudantes que apresentam maior dificuldade de participação, timidez ou pouco interesse pelos assuntos propostos.

De acordo com o Dicionário da Educação Profissional em Saúde ${ }^{20}$,

“... a educação permanente em saúde (EPS) como 'prática de ensinoaprendizagem' significa a produção de conhecimentos no cotidiano das instituições de saúde, a partir da realidade vivida pelos atores envolvidos, tendo os problemas enfrentados no dia-adia do trabalho e as experiências desses atores como base de interrogação $e$ mudança. A educação permanente em saúde se apoia no conceito de 'ensino problematizador' (inserido de maneira crítica na realidade e sem superioridade do educador em relação ao educando) $e$ de 'aprendizagem significativa' (interessada nas experiências anteriores $e$ nas vivências pessoais dos alunos, desafiante do desejar aprender mais), ou seja, ensino-aprendizagem embasado na produção de conhecimentos que respondam a perguntas que pertencem ao universo de experiências e vivências de quem aprende e que gerem novas perguntas sobre o ser $e$ o atuar no mundo" ${ }^{20}$.

A opção pela utilização de um município fictício para a realização das atividades se deu como um disparador para a discussão. Após a aproximação dos alunos com o tema (primeira atividade), cada grupo trabalhou com os dados de saúde dos municípios onde realizavam estágio (atividades dois e três). Os alunos identificaram os entraves e possibilidades reais do SUS, sob as suas perspectivas e trabalharam estas questões nas atividades do eixo de ensino. Assim, a prática não esteve deslocada da teoria, e os conteúdos de gestão puderam ser trabalhados na perspectiva crítico-reflexiva. A Educação Permanente em Saúde (EPS), ao trabalhar com as questões encontradas durante o processo de trabalho, demanda uma ampla reflexão dos profissionais de saúde. Atividades de ensino como a apresentada neste artigo são maneiras de aproximar os estudantes destas ferramentas, reforçando a importância da EPS ao longo de toda sua carreira.

O ensino Odontológico sofreu com o atraso histórico em relação ao modelo tradicional de trabalho em saúde, exigindo um esforço redobrado para que possamos integrar a saúde bucal dentro de um novo contexto de ação interdisciplinar e multiprofissional, formando assim um profissional com perfil adequado ${ }^{18}$. Do período da publicação das DCN em 2002 para o ano de 2020, muitos professores e pesquisadores lançaram mão de ferramentas e metodologias de ensino para qualificar a graduação em Odontologia ${ }^{3,5,6}$. O presente estudo, assim como tantos outros publicados nos últimos anos, 
apresenta-se como um estímulo para que outras instituições de ensino repensem sua forma de trabalho com os estudantes. O compartilhamento de saberes não deve ser apenas entre professor e alunos, mas sim entre toda a comunidade acadêmica, por meio de uma construção colaborativa.

Por ser a primeira experiência tanto da educadora quanto dos educandos neste formato de atividade, existiram algumas limitações e pontos a melhorar. O manejo com a turma foi melhorando à medida que o vínculo foi sendo formado. No entanto, percebe-se a necessidade de amadurecimento da proposta ao longo de sua vivência nas futuras intervenções. Ainda, estratégias de avaliação da proposta pelos estudantes e por outros atores envolvidos, como os profissionais de saúde que recebem os estudantes nas unidades de saúde, também precisam ser desenvolvidas e melhoradas.

\section{CONSIDERAÇÕES FINAIS}

Diante do relato apresentado, percebe-se que a construção das atividades contribuiu para a formação profissional relacionada ao SUS, sua criação e seu funcionamento. No curso de Odontologia da UNIVATES, além de estudarem e participarem dos processos de trabalho no SUS, os estudantes se apropriam sobre a Gestão em Saúde pública. Desta forma, os acadêmicos refletem sobre as complexidades do sistema, tanto como profissionais quanto possíveis gestores, não esquecendo que todos são usuários do SUS.

Cabe ressaltar a dificuldade diante da vasta legislação que dita o funcionamento e o financiamento do SUS. O lançamento das Portarias de Consolidação ${ }^{21}$ objetivou a unificação dos documentos vigentes do SUS. No entanto, percebese que poucos profissionais e estudantes têm conhecimento sobre o tema, e desconhecem as ferramentas para encontrar as leis, portarias e decretos, como o Saúde Legis, Sistema de
Legislação em Saúde que foi disponibilizado pelo governo federal em 2006 e contém os atos normativos pertinentes à saúde.

O perfil do professor é essencial para a construção do trabalho, pois ele deve desprenderse das metodologias tradicionais, e acreditar na autonomia dos estudantes durante as aulas, estimulando-o e orientando-o. A metodologia e a forma como foram ministradas as tarefas oportunizaram a busca ativa e constante pelo conhecimento científico e permitiram uma visão crítica sobre o sistema de saúde brasileiro. O tempo disponibilizado em aula oportunizou diferentes indagações pelos alunos e, juntamente com a orientação da professora, foi possível problematizar e discutir as questões construindo o conhecimento.

É necessário atualizar e dinamizar os conteúdos curriculares, diversificando as metodologias de ensino e lançando mão dos recursos e tecnologias disponíveis pela IES. Neste sentido, as metodologias ativas de ensino e aprendizagem e a construção de projetos são opções válidas aos cursos de Odontologia, pois contribuirá para a formação de seus discentes com uma visão crítica e ampla dos processos práticos, teóricos e sociais. Práticas como a apresentada neste estudo qualificam a formação de acadêmicos instigando a postura crítico-reflexiva e auxiliam o desenvolvimento da capacidade para tomada de decisões e liderança, sem a exaustão de conteúdos teóricos.

O empoderamento que se almeja na saúde perpassa a atitude que os professores devem fomentar em sala de aula. Não basta desejar que os "pacientes" tenham autonomia e que os profissionais sejam corresponsáveis pela saúde da população se essa atitude não for trabalhada com os acadêmicos durante seu processo de formação.

\section{ABSTRACT \\ Project-based Learning and Health Care}


Management: connecting theory and reality in the Unified Health System

The Dentistry Course at Universidade do Vale do Taquari (UNIVATES) is organized through an integrated modular curriculum based on active teaching-learning methodologies. The aim of this study is to report the experience of students and faculty on the 'project-based learning' methodology adopted in the Health, Society, Citizenship and Human Rights VI axis of the Dentistry course in 2018. Students were divided into small groups in order to carry out three main activities: an initial case on health services management; health information systems workshop; and oral health service implementation project. After the completion of each activity, the students presented their work to the entire group for a dialogic analysis. This method aimed to provide full understanding regarding the context of health care spaces, from management to direct user care. The project included the following types of activities: visits to the Health Care Units, analysis of the municipal plans, supervision of the activities and the professionals, contact with users, data research in the health information systems, and analysis on the hiring process of professionals. It was concluded that the students had the opportunity to reflect on the management challenges while dealing with the demands of users and professionals of the Unified Health System (UHS). The teaching method was improved, allowing students and future professionals to build a more critical and expanded perception of the oral health care network. These reflections, based on real situations experienced in the oral health team practice, seek to qualify the work process by training students to work in the UHS.

Descriptors: Learning. Education, Dental. Collective Health. Case Reports. Health Care Management.

\section{REFERÊNCIAS}

1. Mitre SM, Siqueira-Batista R, Mendonça JMG, Morais-Pinto NM, Meirelles CAB, Pinto-Porto $\mathrm{C}$ et al. Metodologias ativas de ensino-aprendizagem na formação profissional em saúde: debates atuais. Ciênc Saúde Coletiva. 2008; 13(Supl 2):2133-44.

2. Toassi RFC, Souza JM, Baumgarten A, Rosing CK. Avaliação curricular na educação superior em odontologia: discutindo as mudanças curriculares na formação em saúde no Brasil. Rev ABENO. 2012; 12(2):170-7.

3. Carrard VC, Montagner F. A iminente revolução no ensino: estamos preparados? Rev ABENO. 2019; 19(3):1.

4. Brasil. Resolução CNE/CES no 3, de 19 de fevereiro de 2002. Diretrizes Curriculares Nacionais do Curso de Graduação em Odontologia. Diário Oficial da União 2002; Seção 1:10.

5. Couto SDAB, Souza PHC. Metodologias ativas como estratégia pedagógica para promoção do ensino-aprendizagem em Odontologia: relato de experiência. Rev ABENO. 2019; 19(2), 91-100.

6. Haddad AE, Macedo MCS, Antoniazzi JH, Souza M, Abdalla CG. Ensinar e aprender por projetos: experiência das disciplinas de teleodontologia e docência universitária. Rev ABENO. 2013; 13(1):72-3.

7. Filatro A, Cavalcanti CC. Metodologias inov-ativas na educação presencial, a distância e corporativa. Saraiva Educação SA; 2018.

8. Paiva MR, Parente JR, Brandão IR, Queiroz AH. Metodologias ativas de ensinoaprendizagem: revisão integrativa. SANARE, 2016;15(2):145-53.

9. Karahoca D, Karahoca A, Uzunboylub H. Robotics teaching in primary school education by project based learning for supporting science and technology courses. Procedia Computer Science 2011; 3:142531.

10. Bender WN. Aprendizagem baseada em 
projetos: educação diferenciada para o século XXI. Penso; 2015.

11. Queiroz JRC, Olivera MDFJ, Cruz Souza DM, Lima AL, Araújo S, Fuscella MAP. Aprendizagem por projeto e inovação tecnológica: união por competências. Rev ABENO. 2016; 16(2):2-6.

12. Costa-Silva D, Côrtes JA, Bachinski RF, Spiegel CN, Alves GG. Teaching cell biology to dental students with a projectbased learning approach. J Dent Educ. 2018; 82(3): 322-31.

13. Rocha NB, Higarashi IH. Ensino de gestão em saúde nos cursos paranaenses de Odontologia. Rev ABENO. 2019; 19(3): 7886.

14. Ceccim RB, Feuerwerker L. O quadrilátero da formação para a área da saúde: ensino, gestão, atenção e controle social. Physis: Rev Saúde Coletiva. 2004; 14: 41-65.

15. Stein C, Warmling CM, Tôrres LHN, Rech RS, Martins AB, Pires FS et al. Laboratório no estágio de gestão do SUS: integração ensino, pesquisa e gestão. Rev ABENO. 2018;18(2):166-73.

16. Freire P. Pedagogia do Oprimido. $60^{\mathrm{a}}$ Edição. Rio de Janeiro, Paz e Terra.

17. Matos EMO, Arreguy IMS, Jamelli SR, Souza FB, Carvalho EJA. Aprendizagem Baseada em Equipes no ensino odontológico: o que pensam os estudantes? Rev ABENO. 2019; 19(4), 91-101.

18. Morita MC, Kriger L. Mudanças nos cursos de Odontologia e a interação com o SUS. Rev ABENO. 2004; 4(1):17-21.
19. Freire P. Pedagogia da Autonomia. 50 Edição. Rio de Janeiro, Paz e Terra.

20. Ceccim RB, Ferla AA. Dicionário da Educação Profissional m Saúde. Educação Permanente em Saúde. [Acesso em: 18 de março de 2020]. Disponível em: http://www.sites.epsjv.fiocruz.br/dicionario /verbetes/edupersau.html.

21. Brasil. Portaria de Consolidação ${ }^{\circ} 1$, de 28 de setembro de 2017. Consolidação das normas sobre os direitos e deveres dos usuários da saúde, a organização e o funcionamento do Sistema Único de Saúde. Brasília: Ministério da Saúde; 2017. [Acesso em: 18 de março de 2020]. Disponível em: http://bvsms.saude.gov.br/bvs/saudelegis/g m/2017/prc0001_03_10_2017.html.

\section{Correspondência para:}

Aline Macarevich Condessa

e-mail: alinemacarevich@yahoo.com.br Rua Professor Cristiano Fischer, 2138/1604 Partenon 91.420-00 Porto Alegre/RS 